\title{
All eyes on the patient: the influence of oncologists' nonverbal communication on breast cancer patients' trust
}

\author{
Marij A. Hillen ${ }^{1} \cdot$ Hanneke C. J. M. de Haes ${ }^{1} \cdot$ Geertjan van Tienhoven $^{2}$ • \\ Nina Bijker ${ }^{2} \cdot$ Hanneke W. M. van Laarhoven $^{3}$ - Daniëlle M. Vermeulen ${ }^{1}$. \\ Ellen M. A. Smets ${ }^{1}$
}

Received: 22 June 2015/Accepted: 24 June 2015/Published online: 31 July 2015

(C) The Author(s) 2015. This article is published with open access at Springerlink.com

\begin{abstract}
Trust in the oncologist is crucial for breast cancer patients. It reduces worry, enhances decision making, and stimulates adherence. Optimal nonverbal communication by the oncologist, particularly eye contact, body posture, and smiling, presumably benefits patients' trust. We were the first to experimentally examine (1) how the oncologist's nonverbal behavior influences trust, and (2) individual differences in breast cancer patients' trust. Analogue patients (APs) viewed one out of eight versions of a video vignette displaying a consultation about chemotherapy treatment. All eight versions varied only in the oncologist's amount of eye contact (consistent vs. inconsistent), body posture (forward leaning vs. varying), and smiling (occasional smiling vs. no smiling). Primary outcome was trust in the observed oncologist (Trust in Oncologist Scale). 214 APs participated. Consistent eye contact led to stronger trust $(\beta=-.13, p=.04)$. This effect was largely explained by lower educated patients, for whom the effect of consistent eye contact was stronger than for higher educated patients $(\beta=.18, p=.01)$. A forward leaning body posture did not influence trust, nor did smiling.
\end{abstract}

Electronic supplementary material The online version of this article (doi:10.1007/s10549-015-3486-0) contains supplementary material, which is available to authorized users.

Marij A. Hillen

m.a.hillen@amc.uva.nl

1 Department of Medical Psychology, Academic Medical Center, University of Amsterdam, P.O. Box 22700, 1100 DE Amsterdam, The Netherlands

2 Department of Radiotherapy, Academic Medical Center, University of Amsterdam, P.O. Box 22700, 1100 DE Amsterdam, The Netherlands

3 Department of Medical Oncology, Academic Medical Center, University of Amsterdam, P.O. Box 22700, 1100 DE Amsterdam, The Netherlands
However, if the oncologist smiled more, he was perceived as more friendly $\left(r_{\mathrm{s}}=.31, p<.001\right)$ and caring $\left(r_{\mathrm{s}}=.18\right.$, $p=.01)$. Older $(\beta=.17, p=.01)$ and lower educated APs $(\beta=-.25, p<.001)$ were more trusting. Trust was weaker for more avoidantly attached APs $(\beta=-.16, p=.03)$. We experimentally demonstrated the importance of maintaining consistent eye contact for breast cancer patients' trust, especially among lower educated patients. These findings need to be translated into training for oncologists in how to optimize their nonverbal communication with breast cancer patients while simultaneously managing increased time pressure and computer use during the consultation.

Keywords Physician-patient relations - Trust . Communication · Nonverbal $\cdot$ Video vignettes · Oncology

\section{Introduction}

Trust in the oncologist is of paramount importance for breast cancer patients [1]. A breast cancer diagnosis comes with uncertain prospects, complex medical information and decisions, and impactful treatment. If cancer patients trust their oncologist in this vulnerable situation, they experience less worry [2,3], improved decision making [4-6], and are more adherent to the oncologist's recommendations [7-9]. Breast cancer patients are on average young and well-informed $[10,11]$. Trust among cancer patients with these characteristics was found to be weaker than average [12]. Therefore, improving trust relations may particularly benefit patients with breast cancer.

Physicians' verbal messages have been shown to influence patients' interpersonal trust [13]. However, how physicians convey the message - their nonverbal communication-is likely as important as the information's verbal 
content [14]. Nonverbal behavior is all communication produced by something other than words [15], and encompasses facial behavior, gaze, interpersonal distance, body movement, touch, vocal behaviors, and more [16]. Nonverbal communication substantially influences one's perception of a conversation [14, 17, 18]. Consequently, it most likely has a crucial influence on trust [19].

Three nonverbal behaviors that are potentially influential for patients' trust in their physician are eye contact, body posture and smiling. First, eye contact most saliently determines patients' perceptions and evaluations of physicians [20]. Consistent eye contact between physicians and their patient is associated with an increase in patients' satisfaction, disclosure and understanding [21-25]. At the same time, the mounting use of computers and electronic patient files during the consultation creates a challenge to physicians in maintaining consistent eye contact with their patient [26, 27]. Nowadays, the computer may even be regarded a 'third person' in the consultation room [28]. The more physicians gaze at their monitor, the less emotionally responsive they may become, causing patients to share less socio-emotional and psychosocial information [29]. Patients may perceive a physician who faces the screen instead of them as less attentive and available [30]. In this light, it is important to know what influence eye contact by the oncologist has on patients' trust.

Second, oncologists' body posture may influence trust. With their posture, physicians can convey their sense of involvement. If physicians keep a smaller physical distance (forward leaning) and a direct body orientation towards the patient, this appears to lead to more positive patient evaluations [31-33]. Oncologists' body posture may, however, be affected by increased time pressure. A perception of restricted time could reduce the sense of involvement oncologists convey to patients. However, the evidence thus far is meager and the influence of oncologists' body orientation on trust has not been investigated to date.

A third nonverbal behavior of particular relevance in oncology, is smiling and the use of humor between physician and patient. Both are not uncommon in the oncology setting, although intuitively, the 'graveness' of the oncology setting does not lend itself for lightheartedness. Nevertheless, a smile within a medical consultation may convey various desirable signals, such as encouragement, sympathy, or understanding [34]. In specific populations of elderly and immigrant cancer patients, occasional smiling by the oncologist appears to enhance trust and satisfaction [35, 36]. However, we do not know whether and how in general, smiling by the oncologist enhances or harms patients' trust.

It should be noted that there is no 'one size fits all' approach to communication. Patients' socio-demographic and personality characteristics may determine how they perceive nonverbal communication and, consequently, their trust. A personality trait consistently linked to trust is patients' attachment style, i.e., how they relate to others in a dependent relationship [37]. People are able to form secure relationships to a higher (securely attached) or lower (insecurely attached) extent. Insecurely attached cancer patients appear to be less trusting of their oncologist [38, 39]. Moreover, they seem to perceive communication differently than securely attached patients [13].

Concluding, both nonverbal communication by the oncologist and characteristics of the patient could influence breast cancer patients' trust in the oncologist. Most of these effects have, however, not been systematically studied. Moreover, all existing evidence for the importance of nonverbal communication is cross-sectional. Studies focusing on breast cancer patients are particularly rare. Therefore, we experimentally tested first, how breast cancer patients' trust can be enhanced through the oncologist's nonverbal communication, focusing on the effects of eye contact, body posture and smiling. Secondary outcomes were patients' likelihood of recommending the oncologist to others and affective perception of the oncologist. Second, we tested how patient characteristics, i.e., age, education and attachment style, influenced trust directly and indirectly, through patients' perception of nonverbal communication.

\section{Methods}

\section{Design}

To investigate effects of isolated nonverbal behaviors experimentally, we used scripted video vignettes, i.e., videotaped medical consultations based on scripts. This prevents practical and ethical issues that would arise from manipulating communication in clinical practice. Video vignettes have proven practical, feasible, and externally valid [13, 40-43].

A basic vignette was created first. Next, variations of this video were created, identical in content except for the nonverbal behaviors displayed by the oncologist. Combining these variations in a $2 \times 2 \times 2$ design resulted in eight different video vignettes. Participants were randomized to video versions. Reported trust in the observed oncologist was the primary outcome. Secondary outcomes were patients' likelihood of recommending the oncologist to others and affectve perception of the oncologist.

\section{Subjects and procedure}

Women participated as analogue patients (APs), i.e., viewing the video while imagining themselves as the 
patient. The validity of the APs approach has been substantiated [40]. However, it is still unclear whether recruiting actual breast cancer patients as APs yields more externally valid results than involving healthy women. Therefore, we approached: (1) patients with a previous breast cancer diagnosis and (2) healthy women of comparable age. Patients were recruited through cancer patient organizations and radiotherapy out-patient clinics of a regional and an academic hospital. They were invited to apply through e-mail (patient organizations) or information letter (out-patient clinics). Healthy women were recruited through a snowballing method, via participating patients.

Applicants were further informed by phone and received an e-mail with a web link to the experiment. Online, APs first filled out a baseline survey assessing socio-demographic and medical background characteristics (T0). Next, they viewed a randomly selected variant of the video. APs were instructed to play the video full screen and sufficiently loud, and to make sure they were not interrupted during viewing. They were specifically instructed to imagine themselves being the patient in the video. After viewing, in a second survey, APs evaluated the observed oncologist (T1, primary and secondary outcomes).

\section{Development of experimental conditions}

Video vignettes development is described in detail in Appendix A (ESM). A basic script was created first, describing a consultation between a medical oncologist and a breast cancer patient about adjuvant chemotherapy after a mastectomy. Whereas such consultations normally last between 15 and $60 \mathrm{~min}$, we shortened our script to last no more than 10 min for practical reasons.

Variations of the basic script were created for the oncologist's amount of eye contact (EYEC+: consistent vs. EYEC-: inconsistent), body posture (BODY+: frontal forward leaning, vs. BODY-: varying), and amount of smiling (SMILING+: occasional vs. SMILING-: never) (see Fig. 1; Box 1). Manipulations were based on previous literature on the effects of nonverbal communication, and on videotapes of radiotherapy consultations [44], in which the naturally occurring variation in nonverbal behaviors was assessed.

Trained actors performed as the (male) oncologist and (female) patient. Pilot-testing was conducted, first on the basic script and second on test-fragments of the video vignettes. Pilot procedures, results and consequent adaptations to the vignettes are described in Appendix A (ESM). Figure 1 illustrates differences between the conditions using screenshots from the videos.

\section{Measures}

Socio-demographic, medical, and personality characteristics (TO)

Age and education level were measured. Among patients, we assessed time since diagnosis, treatment status and number of contacts with their present oncology specialist. Attachment style was measured using the 12-item experiences in close relationships short form (ECR-sf) [39, 45]. The ECR-sf distinguishes two dimensions: attachment anxiety (6 items), a fear of rejection or abandonment and need for approval, and attachment avoidance (6 items), a fear of interpersonal intimacy and need for self-reliance [45]. An example of an item is 'I worry that my close ones won't care about me as much as I care about them' (7point Likert scale, completely disagree $=1$ to completely agree $=7$ ). Reliability was $\alpha=.73$ for attachment avoidance and $\alpha=.76$ for attachment anxiety.

\section{Operationalization success (T1)}

Each video version was scored on: (1) the percentage of time in which the oncologist maintained eye contact with the patient (2) the percentage of time in which the oncologist kept a forward leaning/frontal versus backward leaning/away body posture, and (3) the number of smiles, using behavioral observation software (The Observer [46]). In addition, participants rated their perception of the oncologist's amount of eye contact, physical distance (to assess body posture), and smiling behavior ( 3 single items, 5 -point Likert scale, completely disagree $=1$ to completely agree $=5$ ).

\section{Realism and engagement (T1)}

Three items measured how realistic, credible, and likely to happen in real life patients perceived the video-events (7point Likert scale, completely disagree $=1$ to completely agree $=7$ ). Participants' engagement in the video was assessed using the Video Engagement Scale (VES; 15 items, 7-point Likert scale: completely disagree $=1$ to completely agree $=7$; manuscript submitted) .

Primary outcome: trust in the observed oncologist (T1)

Trust in the observed oncologist was assessed with the 18-item Trust in Oncologist Scale [47, 48]. This scale assesses trust using 18 items, answered on a five-point Likert scale (completely disagree $=1$ to completely agree $=5)$. An example item is 'This doctor strongly 

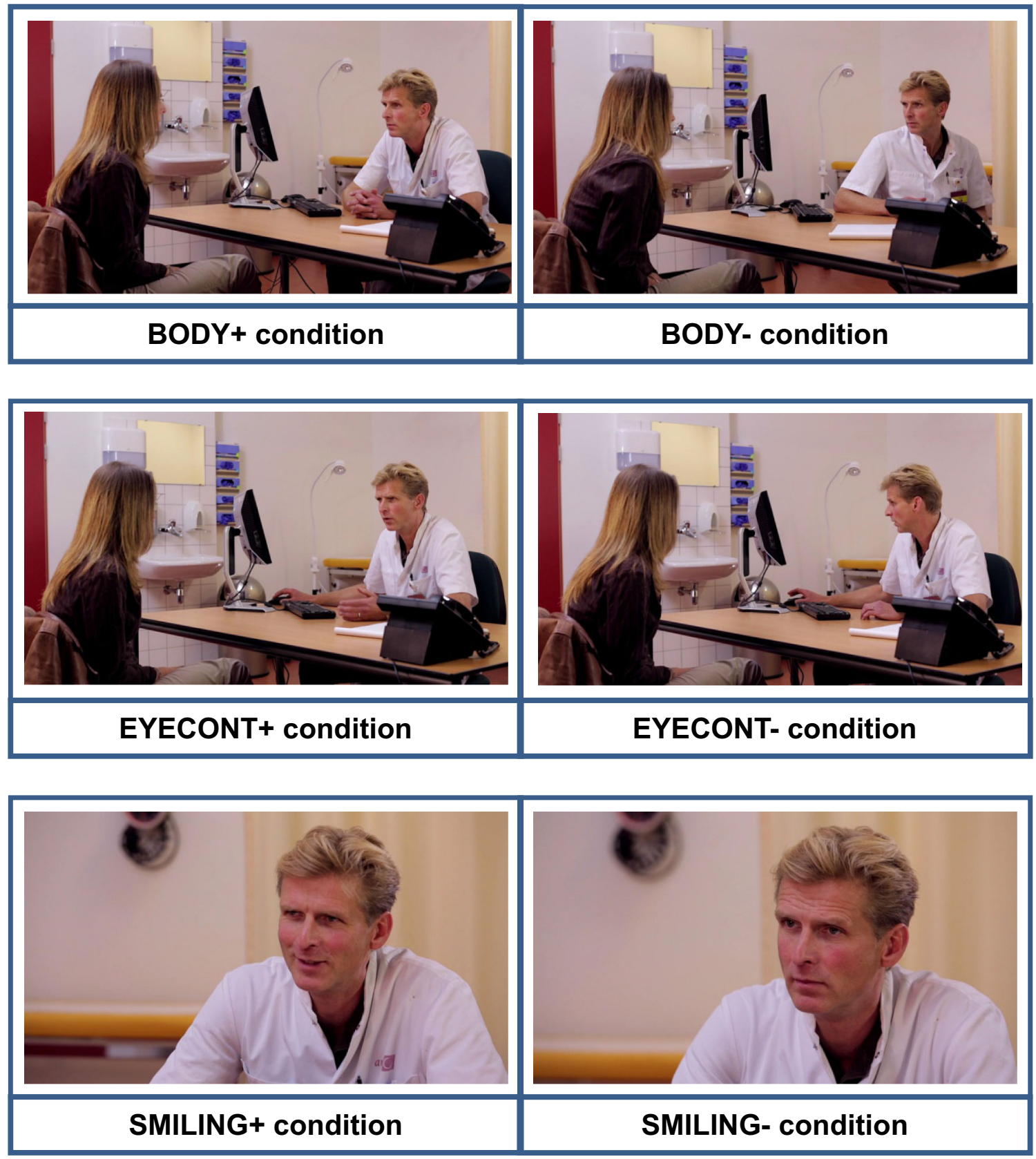

Fig. 1 Illustration of the difference between nonverbal conditions

cares about your health' (5-point Likert scale: completely disagree $=1$ to completely agree $=5$ ). Reliability of the scale was $\alpha=.95$.

\section{Secondary outcome measures (T1)}

The secondary outcomes were participants' (1) likelihood of recommending the oncologist to others and their (2) affective perception of the oncologist, i.e., his competence, friendliness, hurriedness, caring, and honesty. Both were measured with single items, on a five-point Likert scale.

\section{Statistical analysis}

All analyses were conducted using SPSS 20.0 [49]. To test eight effects, i.e., three main effects of the manipulations, three main effects of patients' characteristics (age, education, participant group), and two effects of personality characteristics (attachment anxiety, and attachment avoidance), using an alpha of .05, for a $95 \%$ power to detect medium-sized effects (Cohen's $F^{2}=.15$ ), a minimum sample size of 160 was required [50]. 
Box 1 Specification of nonverbal manipulations

(1) Eye contact

(a) Consistent (EYECONT+): The oncologist retains the patient's gaze throughout the patient's speech and refrains from looking at the computer screen or paperwork while talking or listening

(b) Inconsistent (EYECONT-): The oncologist frequently gazes at the computer screen or paperwork while providing information or when the patient speaks $[24,25,29]$

(2) Body posture

(a) Forward leaning and frontal (BODY+): The oncologist is seated directly facing the patient, leaning slightly forward over the table

(b) Varying (BODY-): The oncologist alternates between a forward leaning, patient-directed posture and a backward leaning posture, leaning away at a $45^{\circ}$ angle from the patient $[31,33]$. Gazing at the computer was intentionally unrelated to leaning away from the patient, to keep the two manipulations distinct

(3) Smiling

(a) Occasional (SMILING+): the oncologist smiles occasionally, especially in the first and final phases of the consultation which involves more social talk. Smiles are modest, conveying understanding or encouragement [34]

(b) Never (SMILING-): the oncologist does not smile throughout the consultation

Using stepwise regression analysis, we first tested the main effects of the nonverbal communication manipulations on trust. Second, APs' background and personality characteristics were added. Third, all possible interactions between communication manipulations and AP characteristics were added to the regression. Regression analyses were repeated, replacing 'trust' with the secondary outcome variable 'likelihood of recommending the oncologist to others'. For regression analyses, all variables were centralized around the mean (continuous variables) or scored as -0.5 versus 0.5 (dichotomous variables). The variable 'education level' was dichotomized as higher (college or university) or lower. Finally, we explored the correlation between nonverbal communication manipulations and APs' affective perception of the oncologist. To account for multiple testing, findings were considered significant at $p<.01$ and marginally significant at $p<.05$.

Table 1 Demographic, health, and relationship characteristics of the sample $(N=214)$

\begin{tabular}{|c|c|c|c|c|}
\hline & \multicolumn{2}{|c|}{ Breast cancer patients $(n=147)$} & \multicolumn{2}{|c|}{ Healthy women $(n=67)$} \\
\hline & Median (range) & SD & Median (range) & SD \\
\hline \multirow[t]{2}{*}{ Age $(n=214)$} & $55(31-91)$ & 11 & $51(31-73)$ & 11 \\
\hline & $N$ & $\%$ & $N$ & $\%$ \\
\hline \multicolumn{5}{|l|}{ Educational level $(n=214)$} \\
\hline None/primary school & 1 & 1 & 0 & 0 \\
\hline Secondary/lower level vocat. school & 84 & 57 & 31 & 46 \\
\hline College/university & 61 & 42 & 36 & 54 \\
\hline \multicolumn{5}{|l|}{ Current living situation $(n=214)$} \\
\hline Alone & 30 & 20 & 6 & 9 \\
\hline With partner & 63 & 43 & 21 & 31 \\
\hline With partner and children & 48 & 33 & 33 & 49 \\
\hline Other & 6 & 4 & 7 & 11 \\
\hline \multicolumn{5}{|l|}{ Self-reported treatment status $(n=147)$} \\
\hline In active treatment (incl. endocrine therapy) & 58 & 39 & & \\
\hline Undergoing regular check ups & 86 & 59 & & \\
\hline \multirow[t]{2}{*}{ No treatment or check ups } & 3 & 2 & & \\
\hline & Mean & SD & & \\
\hline Number of months since diagnosis $(n=139)$ & 42 & 47 & & \\
\hline
\end{tabular}




\section{Results}

\section{Sample}

The sample included 214 participants-147 (69\%) patients and $67(31 \%)$ healthy women (Table 1). Because the questionnaire included forced responses, there were no missing values. Average age was 54 years (range 31-91). Mean trust in the observed oncologist was $3.30(\mathrm{SD}=0.73$, range 1.00-5.00). For attachment anxiety (ECR-sf), average score was $2.72(\mathrm{SD}=1.15$, range $1.00-6.83)$ and for attachment avoidance $2.58(\mathrm{SD}=1.07$, range $1.00-6.00)$.

\section{Manipulation check}

Mean percentage of eye contact in the EYECONT + conditions was $84 \%$ (range 83-85\%), compared to $56 \%$ (range 54-60\%) in the EYECONT - conditions. For the BODY + conditions, forward leaning was observed in $92 \%$ (range $90-94 \%$ ) of the consultation, compared to $62 \%$ (range 60-64\%) in the BODY - conditions. In the SMILING+ conditions, there were on average 8 smiles (range 7-9), compared to 1 smile (range 0-2) in the SMILING- conditions. Participants perceived the eye contact and smiling manipulations as intended: the oncologist in the EYECONT+ was perceived as having more eye contact $(M=3.73, \mathrm{SD}=0.94)$ than in the EYECONT - condition $(M=3.18, \mathrm{SD}=1.08 ; t=-3.96$, $p<.001)$. The oncologist in the SMILING+ conditions was perceived as smiling more $(M=3.20, \mathrm{SD}=0.92)$ than in the SMILING- conditions $(M=2.26, \mathrm{SD}=0.88$; $t=-7.64, p<.001)$. The manipulation for body posture was not consciously perceived: perception of the physical distance between oncologist and patient was equal for the BODY $+(M=3.32, \quad \mathrm{SD}=1.06)$ and the BODY$(M=3.42, \mathrm{SD}=1.05 ; t=0.73$, n.s. $)$ conditions.

\section{The effects of nonverbal communication}

Below, we report results for Step 2 in regression analysis, including all main effects of nonverbal communication and patient characteristics, on trust (Table 2) and 'Likelihood of recommending the oncologist to others' (Table 3). Consistent eye contact led to stronger trust $(\beta=-.13$, $p=.04)$, as well as to a higher reported likelihood of recommending the oncologist to others $(\beta=-.16$, $p=.02)$. Moreover, if the oncologist maintained consistent eye contact, he was perceived as more caring $\left(r_{\mathrm{s}}=.16, p=.02\right)$. Variation in body posture did not influence trust $(\beta=-.08, p=.22)$, nor likelihood of recommending the oncologist to others $(\beta=-.07$, $p=.33$ ). However, forward leaning did cause patients to
Table 2 Main and interaction effects of socio-demographic characteristics, communication manipulations, and attachment on trust $(\mathrm{TiOS})$ in multiple regression analysis

\begin{tabular}{|c|c|c|c|c|}
\hline & $b$ & SE $b$ & $\beta$ & $p$ \\
\hline \multicolumn{5}{|l|}{ Step 1} \\
\hline Constant & 0.00 & .05 & & \\
\hline Eye contact by oncologist & -0.20 & 0.10 & -0.14 & .05 \\
\hline Body posture of oncologist & -0.14 & 0.10 & -0.10 & .17 \\
\hline Smiling by oncologist & -0.14 & 0.10 & -0.10 & .16 \\
\hline \multicolumn{5}{|l|}{ Step 2} \\
\hline Constant & 0.02 & 0.05 & & \\
\hline Eye contact by oncologist & -0.19 & 0.09 & -0.13 & .04 \\
\hline Body posture of oncologist & -0.11 & 0.09 & -0.08 & .22 \\
\hline Smiling by oncologist & -0.11 & 0.09 & -0.08 & .24 \\
\hline Age & 0.01 & 0.01 & 0.17 & .01 \\
\hline Education & 0.36 & 0.10 & 0.25 & $<.001$ \\
\hline Patient type (healthy vs. patient) & 0.19 & 0.10 & 0.12 & .07 \\
\hline Attachment avoidance & -.11 & 0.05 & -0.16 & .03 \\
\hline Attachment anxiety & 0.08 & 0.05 & 0.12 & .09 \\
\hline \multicolumn{5}{|l|}{ Step 3} \\
\hline Constant & 0.02 & 0.05 & & \\
\hline Eye contact by oncologist & -0.15 & 0.09 & -0.10 & .12 \\
\hline Body posture of oncologist & -0.11 & 0.09 & -0.08 & .23 \\
\hline Smiling by oncologist & -0.15 & 0.09 & -0.11 & .11 \\
\hline Age & 0.01 & 0.01 & 0.21 & $<.01$ \\
\hline Education & 0.38 & 0.10 & 0.26 & $<.001$ \\
\hline Patient type (healthy vs. patient) & 0.17 & 0.10 & 0.11 & .10 \\
\hline Attachment avoidance & -0.12 & 0.05 & -0.18 & .02 \\
\hline Attachment anxiety & 0.09 & 0.05 & 0.14 & .05 \\
\hline Eye contact $\times$ age & 0.01 & 0.01 & 0.05 & .48 \\
\hline Eye contact $\times$ education & 0.53 & 0.20 & 0.18 & $<.01$ \\
\hline Eye contact $\times$ attach avoid & -0.06 & 0.10 & -0.04 & .59 \\
\hline Eye contact $\times$ attach anxi & 0.02 & 0.09 & 0.17 & .81 \\
\hline Body posture $\times$ age & 0.01 & 0.01 & 0.06 & .36 \\
\hline Body posture $\times$ education & 0.29 & 0.20 & 0.10 & .14 \\
\hline Body posture $\times$ attach avoid & -0.01 & 0.10 & -0.01 & .90 \\
\hline Body posture $\times$ attach anxi & 0.04 & 0.09 & 0.03 & 67 \\
\hline Smiling $\times$ age & -0.02 & 0.01 & -0.12 & .09 \\
\hline Smiling $\times$ education & -0.31 & 0.19 & -0.11 & .11 \\
\hline Smiling $\times$ attach avoid & 0.10 & 0.10 & 0.07 & .33 \\
\hline Smiling $\times$ attach anxi & -0.08 & 0.09 & -0.06 & .37 \\
\hline
\end{tabular}

$R^{2}=.04$ for Step $1\left(p<.05^{*}\right), \Delta R^{2}=.14$ for Step $2\left(p<.001^{* * *}\right)$, $\Delta R^{2}=.07$ for Step $3(p=.11)$

perceive the oncologist as more medically competent $\left(r_{\mathrm{s}}=.15, p=.03\right)$. Smiling by the oncologist did not enhance trust $(\beta=-.08, p=.24)$ and only slightly increased the likelihood of recommending the oncologist to others $(\beta=-.13, p=.05)$. If the oncologist smiled, he was perceived as more friendly $\left(r_{\mathrm{s}}=.31, p<.001\right)$ and caring $\left(r_{\mathrm{s}}=.18, p=.01\right)$. 
Table 3 Main effects of socio-demographic characteristics, communication manipulations, and attachment on 'likelihood of recommending the oncologist to others' in multiple regression analysis

\begin{tabular}{|c|c|c|c|c|}
\hline & $b$ & SE $b$ & $\beta$ & $P$ \\
\hline \multicolumn{5}{|l|}{ Step 1} \\
\hline Constant & 0.00 & .07 & & \\
\hline Eye contact by oncologist & -0.32 & 0.13 & -0.16 & .02 \\
\hline Body posture of oncologist & -0.13 & 0.13 & -0.07 & .33 \\
\hline Smiling by oncologist & -0.27 & 0.13 & -0.14 & .04 \\
\hline \multicolumn{5}{|l|}{ Step 2} \\
\hline Constant & 0.02 & 0.06 & & \\
\hline Eye contact by oncologist & -0.31 & 0.13 & -0.16 & .02 \\
\hline Body posture of oncologist & -0.11 & 0.13 & -0.06 & .40 \\
\hline Smiling by oncologist & -0.25 & 0.13 & -0.13 & .05 \\
\hline Age & 0.01 & 0.01 & 0.14 & .05 \\
\hline Education & -0.40 & 0.13 & 0.20 & $<.01$ \\
\hline Patient type (healthy vs. patient) & 0.06 & 0.14 & 0.03 & .69 \\
\hline Attachment avoidance & -0.09 & 0.07 & -0.10 & .18 \\
\hline Attachment anxiety & 0.09 & 0.06 & 0.11 & .14 \\
\hline \multicolumn{5}{|l|}{ Step 3} \\
\hline Constant & 0.25 & 0.07 & & \\
\hline Eye contact by oncologist & -0.26 & 0.13 & -0.14 & .04 \\
\hline Body posture of oncologist & -0.13 & 0.13 & -0.07 & .33 \\
\hline Smiling by oncologist & -0.29 & 0.13 & -0.15 & .03 \\
\hline Age & 0.01 & 0.01 & 0.15 & .03 \\
\hline Education & 0.37 & 0.14 & 0.19 & $<.01$ \\
\hline Patient type (healthy vs. patient) & 0.05 & 0.14 & 0.02 & .72 \\
\hline Attachment avoidance & -0.10 & 0.07 & -0.11 & .16 \\
\hline Attachment anxiety & 0.11 & 0.06 & 0.13 & .08 \\
\hline Eye contact $\times$ age & 0.01 & 0.01 & 0.04 & .56 \\
\hline Eye contact $\times$ education & 0.55 & 0.27 & 0.14 & .04 \\
\hline Eye contact $\times$ attach avoid & 0.17 & 0.14 & 0.09 & .22 \\
\hline Eye contact $\times$ attach anxi & -0.15 & 0.13 & -0.09 & .425 \\
\hline Body posture $\times$ age & 0.01 & 0.01 & 0.05 & .46 \\
\hline Body posture $\times$ education & 0.16 & 0.27 & 0.04 & .56 \\
\hline Body posture $\times$ attach avoid & -0.01 & 0.14 & -0.01 & .95 \\
\hline Body posture $\times$ attach anxi & 0.07 & 0.13 & 0.04 & .56 \\
\hline Smiling $\times$ age & -0.02 & 0.01 & -0.11 & .14 \\
\hline Smiling $\times$ education & -0.29 & .27 & -0.08 & .28 \\
\hline Smiling $\times$ attach avoid & 0.23 & 0.14 & 0.12 & .10 \\
\hline Smiling $\times$ attach anxi & -0.18 & .13 & -0.11 & .15 \\
\hline
\end{tabular}

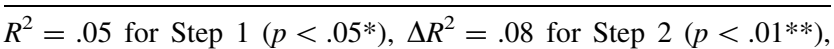
$\Delta R^{2}=.06$ for Step $3(p=.24)$

\section{Patients' socio-demographic characteristics and attachment style as predictors}

Age as well as education level predicted the level of trust in the observed oncologist: older $(\beta=.17, p=.01)$ and lower educated APs $(\beta=-.25, p<.001)$ were more trusting. Older $(\beta=.14, p=.05)$ and lower educated APs were also more likely to recommend the oncologist to others $(\beta=.20, p<.01)$.

Higher attachment avoidance predicted lower trust in the observed oncologist $(\beta=-.16, p=.03)$, but was not related to the likelihood of recommending the oncologist to others $(\beta=-.10, p=.18)$. Higher attachment anxiety did not relate to trust $(\beta=.12, p=.09)$, nor likelihood of recommending the oncologist $(\beta=.11, p=.14)$. In Step 3 , only one of the twelve interactions between patient characteristics and nonverbal communication on trust was significant: the effect of consistent eye contact on trust was only present for APs with a lower education level $(\beta=.18$, $p=.01)$. Inspection of the interaction effect revealed that for highly educated APs (college or university), the effect of eye contact was virtually absent. As a result of adding this interaction effect in Step 3 of regression analysis, the main effect of eye contact on trust became non-significant $(\beta=-.10, p=.12)$.

\section{Discussion}

This is the first experimental study testing the impact of nonverbal communication behavior by the oncologist on breast cancer patients' trust. Results indicate that maintaining eye contact by the oncologist enhanced trust, particularly in the lower educated. A forward leaning and frontal body posture did not significantly improve trust, although it did lead to the oncologist being perceived as more competent. Smiling by the oncologist did not lead to stronger trust. Yet, an oncologist who smiled was perceived as more friendly and caring, and evoked a higher willingness in patients to recommend him to others.

The observed influence of eye contact on trust confirms its importance for rapport building [51]. We experimentally demonstrated this effect, which was previously found only in cross-sectional studies. The extent of eye contact was manipulated independently of other verbal and nonverbal behaviors, ensuring one effect could not be ascribed to other factors. Lower educated breast cancer patients appeared to benefit specifically from consistent eye contact by the oncologist, whereas highly educated patients did not. These results provide useful suggestions to oncologists on how to improve their nonverbal communication, especially with lower educated patients, who are overall more vulnerable. Improved nonverbal communication will contribute to mutual trust.

Maintaining frequent eye contact is hampered by the increasingly dominant role of the computer and use of the electronic health record in the consultation room. In a recent study, a substantial subset of physicians using a health electronic record gazed at the computer during as 
much as $50 \%$ of the consultation [27]. Physicians who spend less time gazing at the computer have more active interactions with their patient [52] and are more patientcentered [53]. Teaching oncologists to manage computer tasks while simultaneously keeping in contact with patients is essential for maintaining good treatment relations. This could mean developing strategies to maintain the flow of conversation while using the computer and preventing periods of extended gaze at the computer and prolonged silence [53]. On the other hand, the advantages of the computer can be maximized, for example, by actively sharing information with patient [54].

Body posture did not influence trust as strongly as expected. This could lead to the conclusion that the oncologist's posture does not contribute to patients' trust. Alternatively, our manipulation may not have been sufficiently strong, as it did not influence viewers' perception of the physical distance kept by the physician. More consistent or drastic changes in the physician's posture might influence patients' perception of the oncologist as distant or hurried and, consequently, impair their trust. In previous research, for example, a standing oncologist was perceived as much less compassionate and calm than one who sat [55, 56]. Standing behavior even affected patients' perception of time: a sitting physician was perceived as spending more time with the patient, even when the consultation was shorter than that of an oncologist who stood [57]. In most Dutch oncology out-patient settings, the oncologist is seated behind a table opposite the patient. The presence of that table allows for less variation in the oncologist's body posture. Nevertheless, physical nearness and attention, expressed by leaning forward over the table and orienting towards the patient, have been consistently linked to patients' positive perceptions of physicians. Thus, future research should shed more light on how physicians can convey an optimal sense of involvement through their posture behind the table and how this relates to trust.

Smiling did not lead to enhanced trust in the present study. Nevertheless, patients did perceive the smiling oncologist as more friendly and caring. Possibly, smiling only influenced the 'caring' dimension of trust, but not other aspects, such as perception of honesty and medical competence [1]. Alternatively, smiling affects trust for a subgroup of patients $[36,58]$. In line with this hypothesis, the observed influence of smiling on trust in this study was stronger for lower educated patients. Possibly, higher educated patients pay more attention to cognitive than to affective aspects of communication.

In addition to nonverbal communication, patients' characteristics predicted breast cancer patients' trust. First, older patients were found to report stronger trust, as in previous studies [59-61]. Second, education predicted trust as well as the likelihood of recommending the oncologist to others. Previous studies provided conflicting evidence about the relation between education level and trust [13, $59,60]$. In the present study, lower educated patients reported significantly stronger trust. Possibly, lowly educated patients take a less critical stance in their relation with the oncologist than those more highly educated. Third, more avoidantly attached patients reported weaker trust in the oncologist, in accordance with previous results [38, 39] and with the well-established difficulty people with avoidant attachment styles have to form trusting relationships $[38,62]$.

All of these individual differences indicate that for certain subgroups of patients, trust is less evident than for others. For oncologists, it is important to realize that younger, higher educated breast cancer patients and patients who are avoidantly attached are less inclined to fully trust them, at least initially. Efforts should be directed at identifying which communication strategies enhance trust among these specific subgroups. For example, to meet avoidantly attached patients' needs, oncologists may emphasize patients' autonomy and independence [62-64]. Younger and higher educated patients may be more likely to consult alternative information sources like the internet, or seek complementary and alternative treatment, which may reduce their trust in the oncologist $[65,66]$. Inquiring about patients' information seeking behavior may raise oncologists' awareness of (the content of) alternative information viewed by the patient. For lower educated patients, efforts can be made to prevent them from blindly and without question obeying the oncologist. Subsequently, oncologists can optimally tailor their communication to patients' background and personality.

A limitation of our study should be acknowledged. The advantages of using an experimental design-i.e., studying behaviors in isolation-also form a disadvantage: in reality, nonverbal behaviors often occur in combinations. Moreover, we could only manipulate three nonverbal behaviors, whereas many other may also be of relevance (paralinguistics, facial expressivity, hand gestures). In the present study, we manipulated only the behaviors most frequently linked to trust. In future studies, other meaningful nonverbal behaviors and combinations of behaviors could be studied.

\section{Conclusion}

This study showed that both nonverbal communication by the oncologist, particularly maintaining eye contact, influences breast cancer patients' trust. These findings need to be translated into training for oncologists focused on maintaining contact nonverbally with breast cancer patients while simultaneously managing the computer and 
increased time pressure. By clarifying which nonverbal communication strategies can be taught and how [67], we can enable evidence-based recommendations for clinical practice. Combined with the earlier established contribution of verbal communication, this study has enabled the further understanding of breast cancer patients' trust in their oncologist.

Acknowledgments Thanks to Pink Ribbon for their assistance in recruiting participants for this study. We are grateful to all breast cancer patients and healthy women for participating in our study. This study was made possible by financial support from the Dutch Pink Ribbon foundation (www.pinkribbon.nl), Grant Number 2011.WO29.C114.

\section{Compliance with ethical standards}

Conflict of interest The authors declare that they have no conflict of interest.

Ethical approval The experiment complies with the current laws of the country in which they were performed. All procedures performed in studies involving human participants were in accordance with the ethical standards of the institutional and/or national research committee and with the 1964 Helsinki declaration and its later amendments or comparable ethical standards. The hospital's Medical Ethics Committee provided an exemption for the study to seek formal approval. The study was registered with the Dutch Trial Registry, with number NTR3934. Informed consent was obtained from all individual participants included in the study.

Open Access This article is distributed under the terms of the Creative Commons Attribution License which permits any use, distribution, and reproduction in any medium, provided the original author(s) and the source are credited.

\section{References}

1. Hillen MA, Onderwater AT, Van Zwieten MCB, de Haes JC, Smets EM (2012) Disentangling cancer patients' trust in their oncologist: a qualitative study. Psychooncology 21(4):392-399

2. Bernstein M, Potvin D, Martin DK (2004) A qualitative study of attitudes toward error in patients facing brain tumour surgery. Can J Neurol Sci 31(2):208-212

3. Knifed E, July J, Bernstein M (2008) Neurosurgery patients' feelings about the role of residents in their care: a qualitative case study. J Neurosurg 108(2):287-291

4. Charles C, Gafny A, Whelan T (2004) Self-reported use of shared decision making among breast cancer specialists and perceived barriers and facilitators to implementing this approach. Health Expect 7:338-348

5. Geller G, Strauss M, Bernhardt BA, Holtzman NA (1997) "Decoding" informed consent. Insights from women regarding breast cancer susceptibility testing. Hastings Cent Rep 27(2):28-33

6. Shepherd HL, Tattersall MH, Butow PN (2008) Physician-identified factors affecting patient participation in reaching treatment decisions. J Clin Oncol 26(10):1724-1731

7. Freedman TG (2003) Prescriptions for health providers: from cancer patients. Cancer Nurs 26(4):323-330

8. Reid CM, Gooberman-Hill R, Hanks GW (2008) Opioid analgesics for cancer pain: symptom control for the living or comfort for the dying? A qualitative study to investigate the factors influencing the decision to accept morphine for pain caused by cancer. Ann Oncol 19(1):44-48

9. Sharf BF, Stelljes LA, Gordon HS (2005) 'A little bitty spot and I'am a big man': patients' perspectives on refusing diagnosis or treatment for lung cancer. Psychooncology 14(8):636-646

10. DeSantis C, Ma J, Bryan L, Jemal A (2014) Breast cancer statistics, 2013. Cancer J Clin 64(1):52-62

11. Jefford M, Tattersall MH (2002) Informing and involving cancer patients in their own care. Lancet Oncol 3(10):629-637

12. Hillen MA, de Haes HC, Smets EM (2011) Cancer patients' trust in their physician: a review. Psychooncology 20(3):227-241. doi:10.1002/pon. 1745

13. Hillen MA, De Haes HCJM, Stalpers LJA, Klinkenbij1 JHG, Eddes EH, Butow PN, van der Vloodt J, van Laarhoven HWM, Smets EMA (2014) How can communication by oncologists enhance patients' trust? An experimental study. Ann Oncol 25(4): 896-901

14. Burgoon JK, Bacue AE (2003) Nonverbal communication skills. In: Green JO, Burleson BR (eds) Handbook of communication and social interaction skills. Erlbaum, Mahwah, NJ, pp 179-219

15. Knapp ML, Hall JA (2009) Nonverbal communication in human interaction, 7th edn. Wadsworth Publishing, Belmont

16. Hall JA, Coats EJ, Lebeau LS (2005) Nonverbal behavior and the vertical dimension of social relations: a meta-analysis. Psychol Bull 131(6):898-924

17. Davenport S, Goldberg D, Millar T (1987) How psychiatric-disorders are missed during medical consultations. Lancet 2(8556): 439-441

18. Mehrabian A (1972) Nonverbal communication. Aldine-Atherton, Chicago

19. Cousin G, Schmid Mast M (2013) Agreeable patient meets affiliative physician: how physician behavior affects patient outcomes depends on patient personality. Patient Educ Couns 90(3):399-404. doi:10.1016/j.pec.2011.02.010

20. Finset A, Del Piccolo L (2010) Nonverbal communication in clinical contexts. In: Rimondini M (ed) Communication in cognitive behavioral therapy, 1st edn. Springer, New York, pp 107-127

21. Gorawara-Bhat R, Cook MA (2011) Eye contact in patient-centered communication. Patient Educ Couns 82(3):442-447

22. Smith CK, Polis E, Hadac RR (1981) Characteristics of the initial medical interview associated with patient satisfaction and understanding. J Fam Pract 12(2):283-288

23. Bensing JM, Kerssens JJ, Vanderpasch M (1995) Patient-directed gaze as a tool for discovering and handling psychosocial problems in general-practice. J Nonverbal Behav 19(4):223-242

24. Hall JA, Harrigan JA, Rosenthal R (1995) Nonverbal behavior in clinician patient interaction. Appl Prev Med 4(1):21-37

25. Griffith CH, Wilson JF, Langer S, Haist SA (2003) House staff nonverbal communication skills and standardized patient satisfaction. J Gen Intern Med 18(3):170-174

26. Duke P, Frankel RM, Reis S (2013) How to integrate the electronic health record and patient-centered communication into the medical visit: a skills-based approach. Teach Learn Med 25(4): 358-365

27. Asan O, Montague E (2012) Physician interactions with electronic health records in primary care. Health Syst 1(2):96-103. doi:10.1057/hs.2012.11

28. Bensing J, Tromp F, Dulmen S, Brink-Muinen A, Verheul W, Schellevis F (2006) Shifts in doctor-patient communication between 1986 and 2002: a study of videotaped general practice consultations with hypertension patients. BMC Fam Pract 7(1):62

29. Margalit RS, Roter D, Dunevant MA, Larson S, Reis S (2006) Electronic medical record use and physician-patient communication: an observational study of Israeli primary care encounters. Patient Educ Couns 61(1):134-141 
30. Robinson JD (2006) Non-verbal communication and physicianpatient interaction: review and new directions. In: Manusov V, Patterson ML (eds) The SAGE handbook of nonverbal communication. Sage Publications, Thousand Oaks, pp 437-460

31. Weinberger M, Greene JY, Mamlin JJ (1981) The impact of clinical encounter events on patient and physician satisfaction. Soc Sci Med 15(3):239-244

32. Harrigan JA, Oxman TE, Rosenthal R (1985) Rapport expressed through nonverbal behavior. J Nonverbal Behav 9(2):95-110

33. Larsen KM, Smith CK (1981) Assessment of nonverbal-communication in the patient: physician interview. J Fam Pract 12(3):481-488

34. Henry SG, Fuhrel-Forbis A, Rogers MAM, Eggly S (2012) Association between nonverbal communication during clinical interactions and outcomes: a systematic review and meta-analysis. Patient Educ Couns 86(3):297-315

35. Greene MG, Adelman RD, Friedmann E, Charon R (1994) Older patient satisfaction with communication during an initial medical encounter. Soc Sci Med 38(9):1279-1288

36. Hillen MA, El Temna S, van der Vloodt J, de Haes JCJM, Smets EMA (2013) Vertrouwen van Turkse en Arabische allochtonen in hun oncoloog [Trust of Turkish and Arabic ethnic minority patients in their Dutch oncologist]. Ned Tijdschr Geneeskd 157(18):828-833

37. Salmon P, Young B (2009) Dependence and caring in clinical communication: the relevance of attachment and other theories. Patient Educ Couns 74(3):331-338. doi:10.1016/j.pec.2008.12. 011

38. Holwerda N, Sanderman R, Pool G, Hinnen C, Langendijk JA, Bemelman WA, Hagedoorn M, Sprangers MAG (2013) Do patients trust their physician? The role of attachment style in the patient-physician relationship within one year after a cancer diagnosis. Acta Oncol 52(1):110-117

39. Hillen MA, De Haes HCJM, Stalpers LJA, Klinkenbijl JHG, Eddes EH, Verdam MGE, Smets EMA (2014) How attachment style and locus of control influence patients' trust in their oncologist. J Psychosom Res 76(3):221-226

40. Van Vliet LM, Verheul W, Van der Wall E, Bensing JM (2012) The validity of using analogue patients in practitioner-patient communication research: systematic review and meta-analysis. J Gen Intern Med 27(11):1528-1543

41. Fogarty LA, Curbow BA, Wingard JR, McDonnell K, Somerfield MR (1999) Can 40 s of compassion reduce patient anxiety? J Clin Oncol 17(1):371-379

42. Saha S, Beach MC (2011) The impact of patient-centered communication on patients' decision making and evaluations of physicians: a randomized study using video vignettes. Patient Educ Couns 84(3):386-392

43. Van Vliet LM (2013) Balancing explicit with general information and realism with hope. Communication at the transition to palliative breast cancer care. Utrecht University, Utrecht

44. Douma KFL, Koning CCE, Zandbelt LC, De Haes HCJM, Smets EMA (2012) Do patients' information needs decrease over the course of radiotherapy? Support Care Cancer 20(9):2167-2176

45. Wei M, Russell DW, Mallinckrodt B, Vogel DL (2007) The experiences in close relationship scale (ECR)-short form: reliability, validity, and factor structure. J Personal Assess 88(2):187-204

46. Noldus LPJJ (1991) The observer: a software system for collection and analysis of observational data. Behav Res Methods Instrum Comput 23(3):415-429

47. Hillen MA, Koning CCE, Wilmink JW, Klinkenbij1 JHG, Eddes EH, Kallimanis-King BL, de Haes JCJM, Smets EMA (2012) Assessing cancer patients' trust in their oncologist: development and validation of the Trust in Oncologist Scale (TiOS). Support Care Cancer 20(8):1787-1795. doi:10.1007/s00520-011-1276-8
48. Hillen MA, Butow PN, Tattersall MHN, Hruby G, Boyle FM, Vardy J, Kallimanis-King BL, de Haes JCJM, Smets EMA (2013) Validation of the English version of the Trust in Oncologist Scale (TiOS). Patient Educ Couns 91(1):25-28

49. IBM SPSS Statistics for Windows, Version 20.0 (2011) IBM Corp, Armonk, NY

50. Faul F, Erdfelder E (1992) GPOWER: a priori, post-hoc, and compromise power analyses for MS-DOS (computer program). Department of Psychology, Bonn University, Bonn

51. MacDonald K (2009) Patient-clinician eye contact: social neuroscience and art of clinical engagement. Postgrad Med 121(4):136-144

52. Gibbings-Isaac D, Iqbal M, Tahir MA, Kumarapeli P, de Lusignan S (2012) The pattern of silent time in the clinical consultation: an observational multichannel video study. Fam Pract 29(5):616-621

53. Street RL Jr, Liu L, Farber NJ, Chen Y, Calvitti A, Zuest D, Gabuzda MT, Bell K, Gray B, Rick S, Ashfaq S, Agha Z (2014) Provider interaction with the electronic health record: the effects on patient-centered communication in medical encounters. Patient Educ Couns 96(3):315-319. doi:10.1016/j.pec.2014.05.004

54. Asan O, Young HN, Chewning B, Montague E (2015) How physician electronic health record screen sharing affects patient and doctor non-verbal communication in primary care. Patient Educ Couns 98(3):310-316

55. Strasser F, Palmer JL, Willey J, Shen L, Shin K, Sivesind D, Beale E, Bruera E (2005) Impact of physician sitting versus standing during inpatient oncology consultations: patients' preference and perception of compassion and duration. A randomized controlled trial. J Pain Symptom Manag 29(5):489-497. doi:10. 1016/j.jpainsymman.2004.08.011

56. Bruera E, Palmer JL, Pace E, Zhang K, Willey J, Strasser F, Bennett MI (2007) A randomized, controlled trial of physician postures when breaking bad news to cancer patients. Palliat Med 21(6):501-505

57. Swayden KJ, Anderson KK, Connelly LM, Moran JS, McMahon JK, Arnold PM (2012) Effect of sitting vs. standing on perception of provider time at bedside: a pilot study. Patient Educ Couns 86(2):166-171

58. Stepanikova I, Zhang Q, Wieland D, Eleazer GP, Stewart T (2012) Non-verbal communication between primary care physicians and older patients: how does race matter? J Gen Intern Med 27(5):576-581. doi:10.1007/s11606-011-1934-z

59. O'Malley AS, Sheppard VB, Schwartz M, Mandelblatt J (2004) The role of trust in use of preventive services among low-income African-American women. Prev Med 38(6):777-785

60. Kraetschmer N, Sharpe N, Urowitz S, Deber RB (2004) How does trust affect patient preferences for participation in decision making? Health Expect 7(4):317-326

61. Gordon HS, Street RL Jr, Sharf BF, Kelly PA, Souchek J (2006) Racial differences in trust and lung cancer patients' perceptions of physician communication. J Clin Oncol 24(6):904-909

62. Tan A, Zimmermann C, Rodin G (2005) Interpersonal processes in palliative care: an attachment perspective on the patient-clinician relationship. Palliat Med 19(2):143-150

63. Hunter JJ, Maunder RG (2001) Using attachment theory to understand illness behavior. Gen Hosp Psychiatry 23(4):177-182

64. Dozier M, Cue KL, Barnett L (1994) Clinicians as caregivers: role of attachment organization in treatment. J Consult Clin Psychol 62(4):793-800

65. Salt E, Rayens MK, Kerr AM, Alikhan M, Crofford LJ (2015) Examining rheumatoid arthritis patients' trust in their provider over time: the effects of demographic factors and accessing sources of information. Orthop Nurs 34(3):159-165. doi:10.1097/ NOR.0000000000000145 
66. Corner J, Yardley J, Maher E, Roffe L, Young T, Maslin-Prothero S, Gwilliam C, Haviland J, Lewith G (2009) Patterns of complementary and alternative medicine use among patients undergoing cancer treatment. Eur J Cancer Care 18(3):271-279
67. Crane J, Crane FG (2010) Optimal nonverbal communications strategies physicians should engage in to promote positive clinical outcomes. Health Mark Q 27(3):262-274. doi:10.1080/ 07359683.2010.495300 